\title{
Beobachtungen zur Baugeschichte der Basler „Pfalz“ anlässlich der Sanierung 1994/95
}

\author{
Daniel Reicke
}

\section{Einleitung}

Die Stützmauer der allen Baslern als „Pfalz” bekannten Aussichtsplattform beim Münster musste in den Jahren 1994 und 1995 ausgebessert werden. Die unter Regie der Münsterbauhütte von Privatfirmen ausgeführten Arbeiten erfolgten in zwei Etappen: 1994 wurde die rheinabwärts gelegene Hälfte der Mauer saniert, im folgenden Jahr die andere Hälfte ${ }^{1}$. Dabei sind die zu Beginn unseres Jahrhunderts mit Zement verstrichenen Steinfugen neu mit Kalkmörtel ausgestrichen worden, um weitere Frostschäden zu vermeiden; einzelne Quader mussten zur Stabilisierung der Mauer geflickt werden. Ausserdem wurde der durch Wurzeln unstabil gewordene Teil der Brüstungsmauer in der südöstlichen Ecke der Pfalzterrasse abgebaut und neu gesetzt (Abb. 1). Und schliesslich wurde ein Sondiergraben von rund einem Meter Tiefe längs der Innenfront der Stützmauer ausgehoben, um - zur bes-

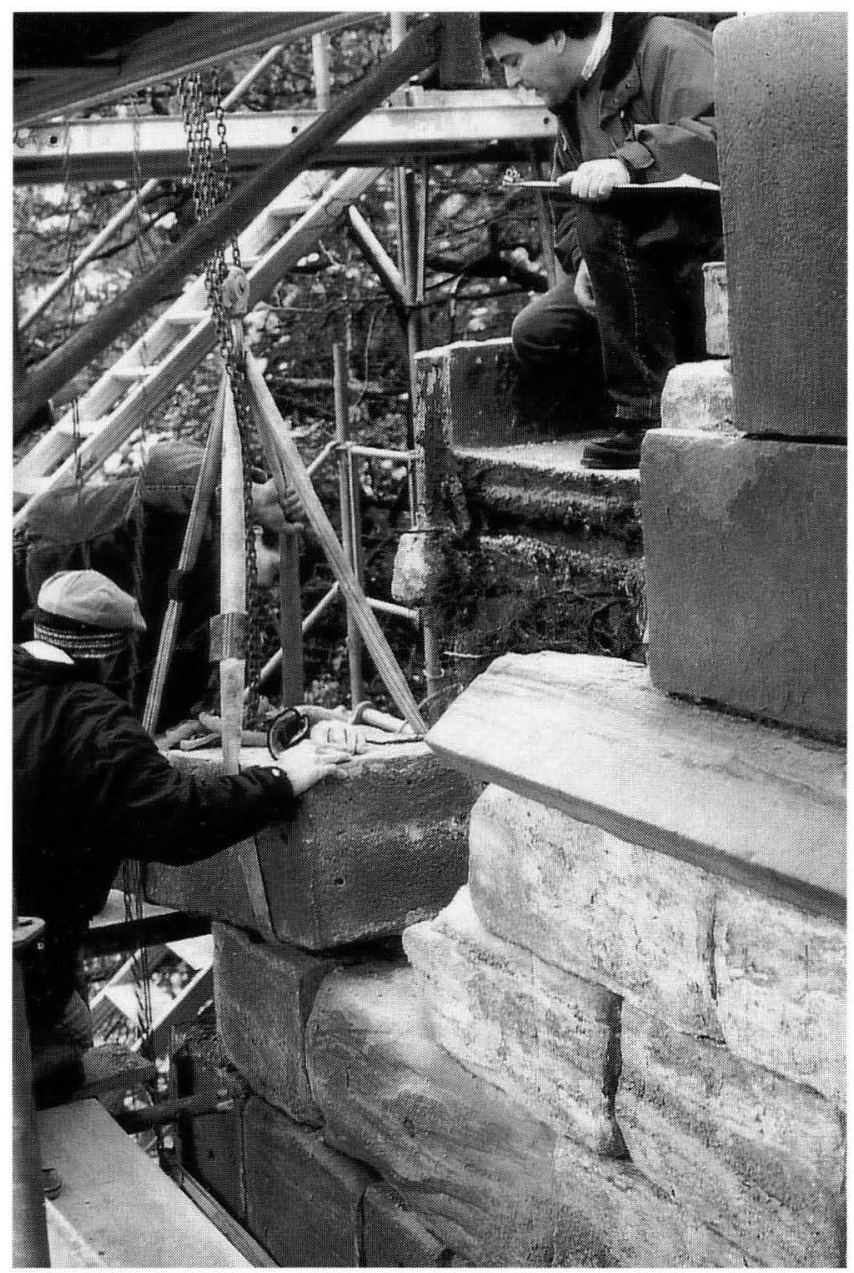

Abb. 1. Südöstliche Ecke der Pfalzmauer beim Neuversetzen der Steine. - Foto: BaDpfl. seren Abdichtung gegen Regenwasser - im Bereich des geteerten Gehsteigs den Belag erneuern zu können².

Die beiden Skulpturen an der Aussenseite der Pfalzmauer, die Marienfigur an der südöstlichen Ecke und die Statue Kaiser Heinrichs in der Mitte (Abb. 8), waren stark verwittert. Die Münsterbauhütte erhielt den Auftrag, Kopien derselben herzustellen (Abb. 2). Die Originale befinden sich jetzt in der Sammlung der Münsterskulpturen im Kleinen Klingental.

Die insgesamt $45 \mathrm{~m}$ (unten gemessen) lange und $18 \mathrm{~m}$ hohe Stützmauer besteht bei genauerer Betrachtung aus verschiedenen Teilen (Abb. 8). Die untere Hälfte wird aus Buckelquadern gebildet, die obere aus glatt behauenen Quadern. Der obere Teil erhebt sich über einem Kaffgesims, das in der Mitte um vier Steinlagen springt, d.h. an der nordwestlichen Hälfte der Mauer (rechts vom Betrachter aus) setzt das Gesims leicht höher an. In der Mitte wächst ein Pfeiler aus dem Gesims, der mit der Skulptur Heinrichs geschmückt ist und die polygonale, aus der Front hervorspringende Aussichtskanzel trägt. - Unten steht zudem an den Ecken der Front je ein pfeilerartiger Vorsprung; der linke bzw. südöstliche ist $4,5 \mathrm{~m}$ breit und $7 \mathrm{~m}$ hoch, der rechte bzw. nordwestliche misst hingegen 17,5 m in der Breite und 5,5 $\mathrm{m}$ in der Höhe. Am oberen Abschluss dieses breiten Vorsprungs finden sich Reste eines Gesimsprofils mit einem Rundstab, der Vorsprung führt ohne Unterbruch über die Nordwestecke hinaus, wo er auch den Unterbau der Treppe bildet. Die Treppe, genauer deren oberer Teil, ist an einem Wasserspeier inschriftlich in das Jahr 1723 datiert.

\section{Zur historischen Überlieferung}

In seiner Basler Geschichte nannte Rudolf Wackernagel den Münsterhügel das Kapitol von Basel ${ }^{3}$. Die hier hinter dem Münster zum Rhein hin gelegene Pfalz ist ein für das Stadtbild wichtiges Element, ein Wahrzeichen der Stadt. Weshalb die Pfalz die sonst für Königs- oder Herrscherresidenzen übliche Bezeichnung erhielt, ist nicht bekannt; Wackernagel vermutet im Anschluss an Daniel Fechter, dass hier eine Zeit lang der Bischofshof stand ${ }^{4}$. Ich möchte aber auf die Frage des Namens nicht weiter eingehen, da im folgenden vorwiegend das Alter bzw. die Bauphasen der Pfalzmauer diskutiert werden sollen.

Bezüglich der Erwähnungen der Pfalz in Chroniken und anderen Quellen können wir Karl Stehlin folgen. Er hat in seiner Baugeschichte des Basler Münsters diesbezügliche Angaben Christian Wurstisens, des Basler Chronisten des 16. Jahrhunderts, berücksich- 


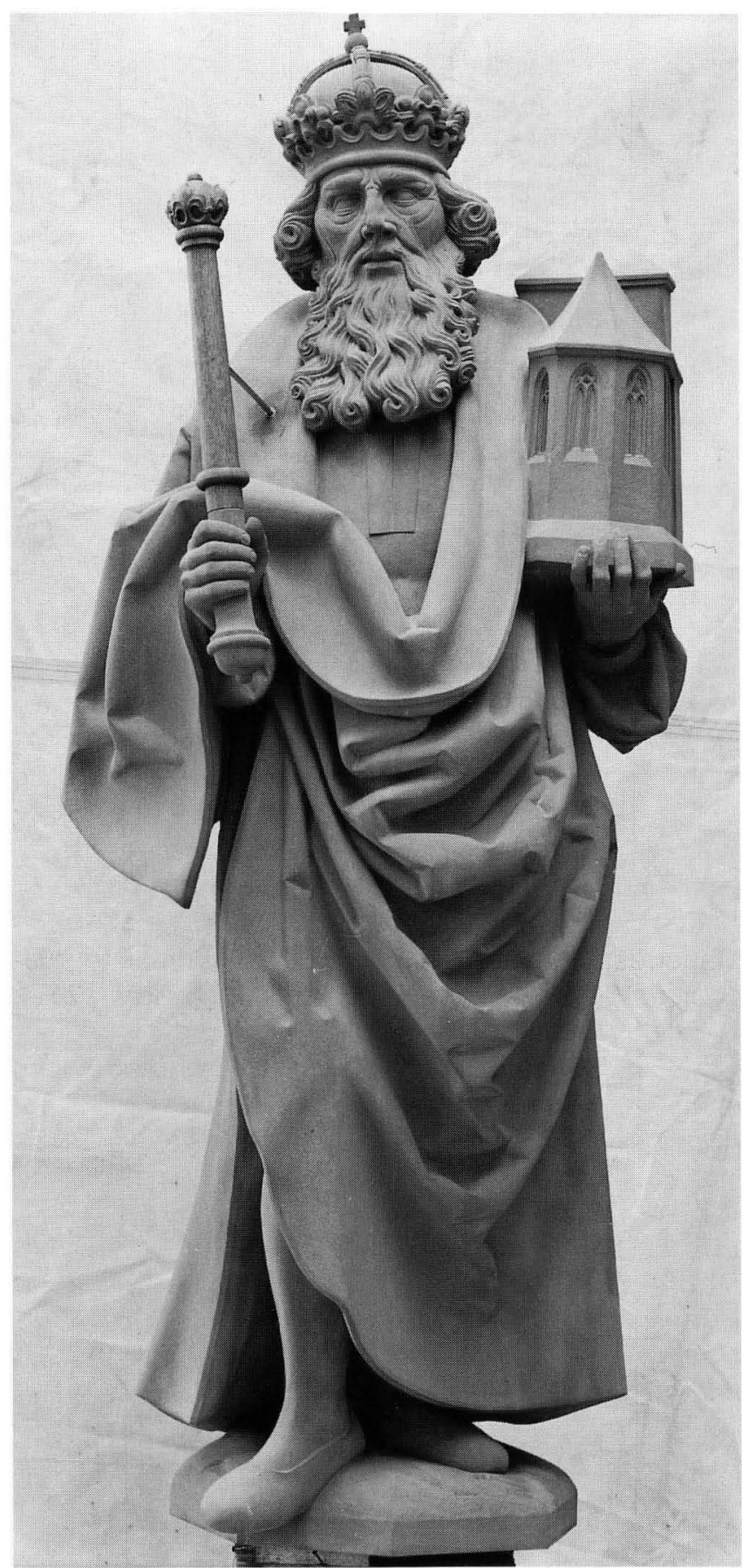

Abb. 2. Kopie der Statue Kaiser Heinrichs in der Mitte der Pfalzmauer, direkt unter der Kanzel (vgl. Abb. 10). - Foto: Erik Schmidt.

tigt und einer kritischen Sichtung unterzogen ${ }^{5}$ (, da einzelne Angaben Wurstisens in den „Analecta” nicht mit den Aussagen in seiner Münsterbeschreibung übereinstimmen).

Der früheste bekannte Nachweis der Pfalz findet sich in der Chronik des Johannes Vitoduranus, wo für ca. 1330 festgehalten ist, dass damals ein päpstlicher Gesandter von der Pfalz gestürzt worden sei, den Fall aber überlebt habe ${ }^{6}$. Die späteren Erwähnungen betreffen vorwiegend Einstürze der Mauer: so z.B. einen Einsturz im Jahre 1346, Sanierungsarbeiten in den Jahren 1467-69 sowie einen erneuten Einsturz 15027 .
Erstaunlich ist, dass die Pfalz nach einer Sanierung des Fundamentes in den Jahren 1467-1469 bereits am 8. Januar 1502 wieder teilweise einstürzte. Wie gross die damals zerstörten und erneuerten Mauerteile wirklich waren, soll uns im Folgenden aufgrund der Beobachtungen am Bau beschäftigen.

Aus den von Wurstisen überlieferten Fabrikrechnungen $^{8}$ seien hier einige etwas rätselhafte Beobachtungen wiedergegeben, die beim Neubau der Pfalz ab 1503 gemacht worden sind: „1503 hatt man angfangen graben auf der Pfalz, und dz bey 6 Absätz seind gwesen angfangen bey 12 Schuch tief, unnd nach allem absetzen, ist die vorder Mauer mit dem abgefallnen Theil gsin 11 Schu dick. Item an der selben Mur gegen dem Münster, ist ein Schu under dem letsten Absatz ein Maur gfunden, als lang als die Pfaltz ist, wider den Rhein 11 schu dick, an der vorgeschribnen Maur der Lenge nach. Item von derselben Mur an der Mitte ein Strebmaur ...". Es folgt die Beschreibung eines Strebepfeilers von 7 Schuh Dicke, der zum Chor hin ansteige und dabei gegen oben hin dicker werde. 1503 habe man 11 Schiffsladungen Warmbacher Quader verbaut für die neue Mauer, die 9 Schuh dick erstellt wurde. Dann habe die Bauhütte ein eigenes Schiff gekauft und in den folgenden Jahren damit etwa hundert Ladungen Quader geführt. Zu den Massangaben sei ergänzend beigefügt: Die 11 Schuh Dicke der oben zitierten vorderen Mauer entsprechen etwa 3,5 m. Die neue Mauer erhielt eine Stärke von 9 Schuh, das sind rund 2,9 m; dieses Mass stimmt mit der am oberen Ende der Pfalz anlässlich der Sanierung 1994/95 eingemessenen Breite von 2,8 m weitgehend überein. Bei der Längsmauer, die gemäss Bericht unter dem letzten Absatz gefunden wurde, könnte es sich um den Rest einer Vorgängermauer handeln; sie soll wie die 1502 zerstörte Mauer 11 Schuh dick gewesen sein. Weil die jetzt erfolgten Eingriffe aber nicht bis in diese Tiefe hinabreichten, können wir zu diesem Mauerrest nichts sagen.

Zu den Ursachen des Einsturzes von 1502: Karl Stehlin hält aufgrund der Quellen fest, dass der damalige Einsturz nicht auf den Erddruck des Hanges zurückzuführen ist, sondern darauf, dass das Fundament vom Rhein „underfressen” war ${ }^{9}$. Für eine Unterspülung sprechen auch zwei weitere Umstände: Die neu errichtete Mauer war wie erwähnt weniger dick als die alte, zudem wurde um 1510 als Schutz vor dem Wasser eine neue Aufschüttung am Fuss der Mauer angelegt. Als weitere Ursache des Einsturzes ist aber auch eine Frostsprengung in Betracht zu ziehen, v.a: in Anbetracht der Jahreszeit, zu der sich der Einsturz ereignete (8. Januar). Der Schaden von 1502 kann letztlich auch durch zwei verschiedene Ursachen ausgelöst worden sein. Auf die hier aufgeworfenen Fragen komme ich unten nochmals kurz zurück.

Die Fabrikrechnungen ${ }^{10}$ belegen, dass grosse Teile des heutigen Bestands auf die Erneuerung von 1503-10 zurückgehen. Der Neubau der Pfalzmauer lag in den Händen von Baumeister Remigius oder Ruman Faesch, 
dem Erbauer der Schlüsselzunft und der Gewölbe in der Kartäuserkirche, der 1503 als Werkmeister des Basler Münsters zusammen mit seinem Sohn Paul als Polier angestellt wurde ${ }^{11}$. Dieses Baudatum der Pfalz bzw. ihres oberen Teils wird auch durch die Gestaltung der Brüstung, des Erkers und der Skulpturen nahegelegt, d.h. die obere Hälfte des Bauwerks darf als das Werk der Baumeister Faesch gelten. Uns stellt sich aber die Frage, ob nicht im unteren Teil - wo die Mauer aus rohen Buckelquadern besteht - Reste älterer Mauern stecken (s. unten: Die Steinmetzzeichen)

Die historischen Abbildungen der Pfalz geben für die hier angesprochenen Belange nicht viel her. Die einzige Darstellung mit Aussagekraft zu Details am Bau ist die Stadtansicht Matthäus Merians d.Ä. von 1615/17 (Abb. 3). Die Pfalz besteht hier aus einem unteren Teil aus Buckelquadern und einem oberen glatt erbauten Teil - was weitgehend dem heutigen Zustand entspricht. Die Buckelquader reichen bei Merian, wie heute noch, in der nordwestlichen Hälfte einige Steinlagen höher als in der anderen (Abb. 8). Über eventuelle mittelalterliche Partien, die in der Mauer erhalten geblieben wären, gibt die Abbildung natürlich keine Auskunft.

\section{Besonderheiten an der Pfalzmauer}

Wie eben erwähnt, liegt das mittlere Gesims in der nordwestlichen Hälfte der Mauer vier Steinlagen höher als im südöstlichen Teil (Abb. 8). Als weitere Un-

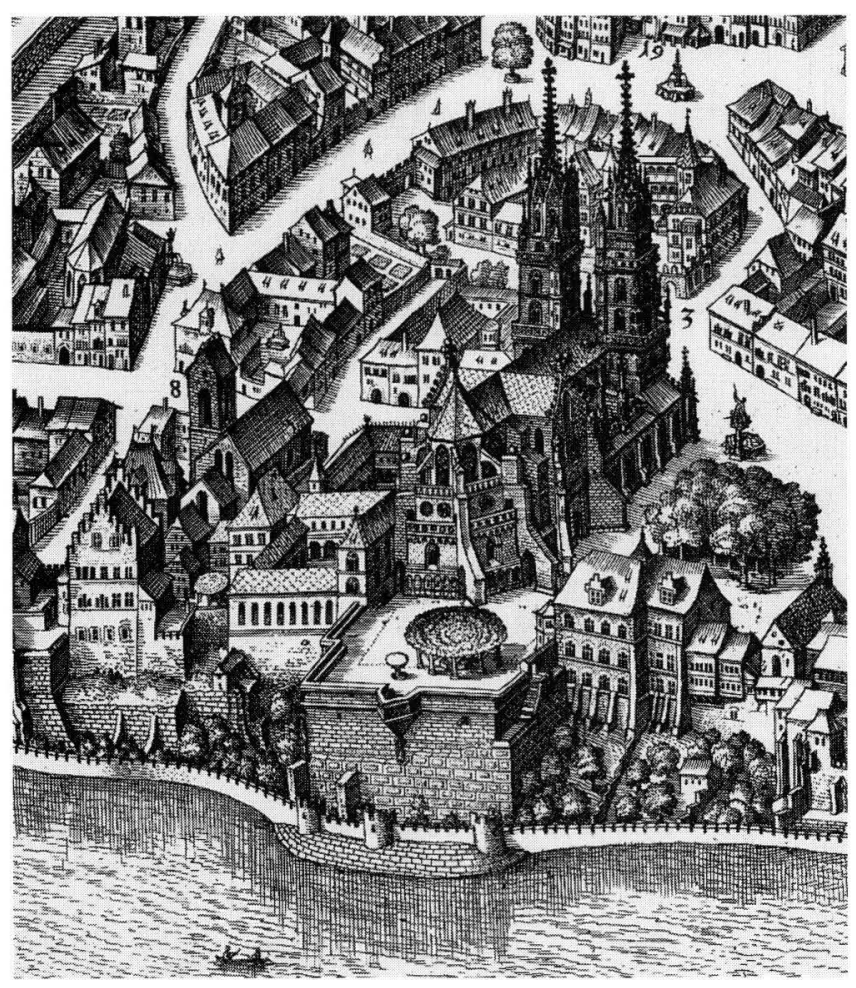

Abb. 3. Vogelschauplan der Stadt Basel (Ausschnitt) von Matthäus Merian d.Ä., Ansicht von Norden, 1615/17.

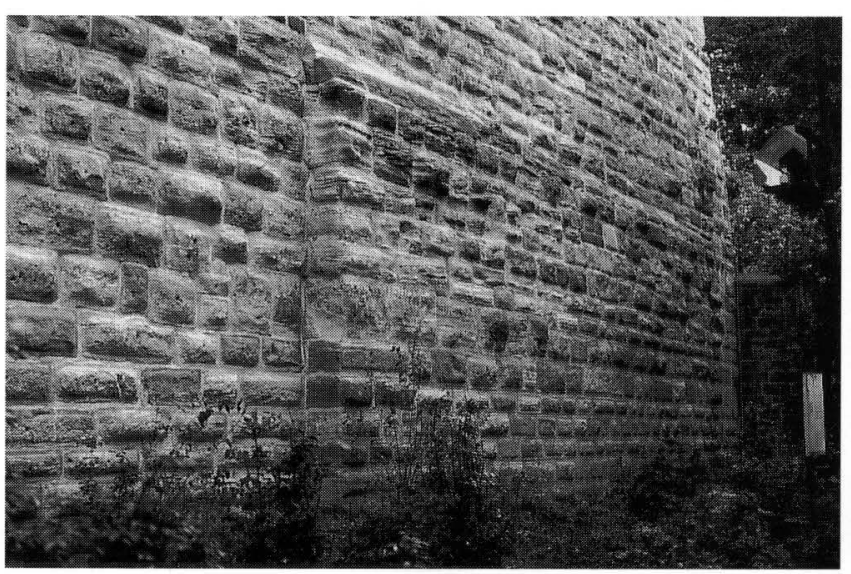

Abb. 4. Vorspringender nordwestlicher Teil der Pfalzmauer mit dem unteren wulstförmigen Gesims. - Foto: BaDpfl.

regelmässigkeiten sind die zwei ungleich breiten, je rund 15 Steinlagen hohen, strebepfeilerartigen Vorsprünge am unteren Mauerteil zu erwähnen (Abb. 8). Der breitere nordwestliche Vorsprung der Mauer (Abb. 4) endet oben in einem waagrechten, stark verwitterten Rundstab oder Wulstprofil - ein mögliches Indiz dafür, dass in der Pfalzmauer ein spätromanischer Mauerrest enthalten sein könnte. Der schmalere südöstliche Vorsprung zeigt keinen entsprechenden Wulst, obwohl er den anderen Mauervorsprung um rund einen Meter überragt. Die Unregelmässigkeiten bzw. deren genauer Zusammenhang können nicht erklärt werden, stützen aber die Annahme älterer Baureste.

\section{Die Steinmetzzeichen}

Am Fuss des südöstlichen Vorsprungs der Pfalzmauer finden sich vier Steinmetzzeichen, die auf den ersten Blick altertümlich aussehen (Abb. 5 und Abb. 6). Charakteristisch ist deren grosse, einfache Form. Ähnlich

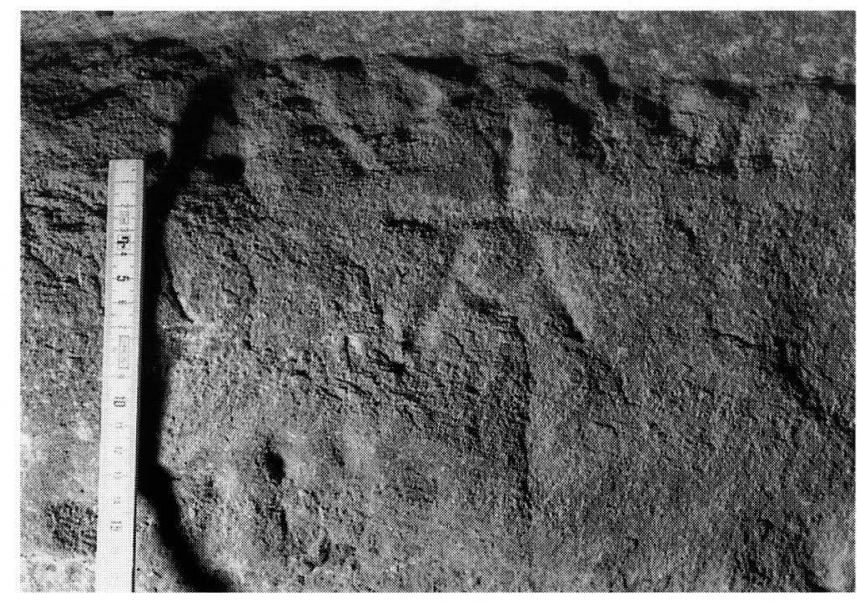

Abb. 5. Eines der vier alten Steinmetzzeichen am Fuss der Pfalz. - Foto: BaDpfl. 

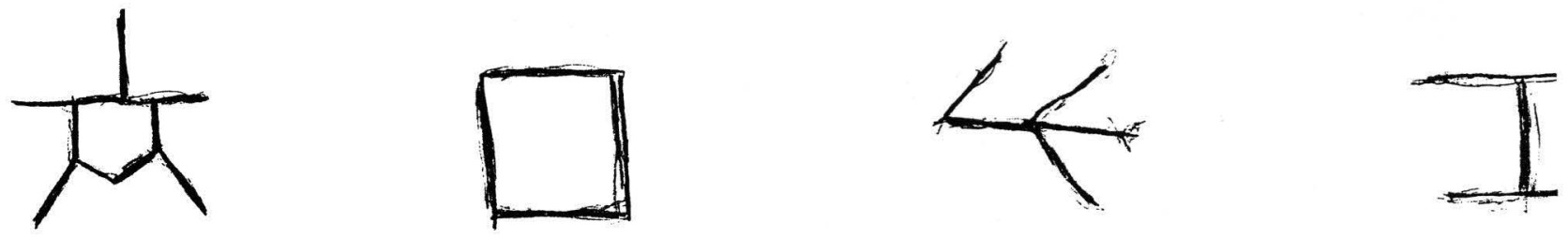

Abb. 6. Abriebe der alten Steinmetzzeichen am Fuss der Pfalz. - Aufnahme: D. Reicke. - Massstab 1:4.
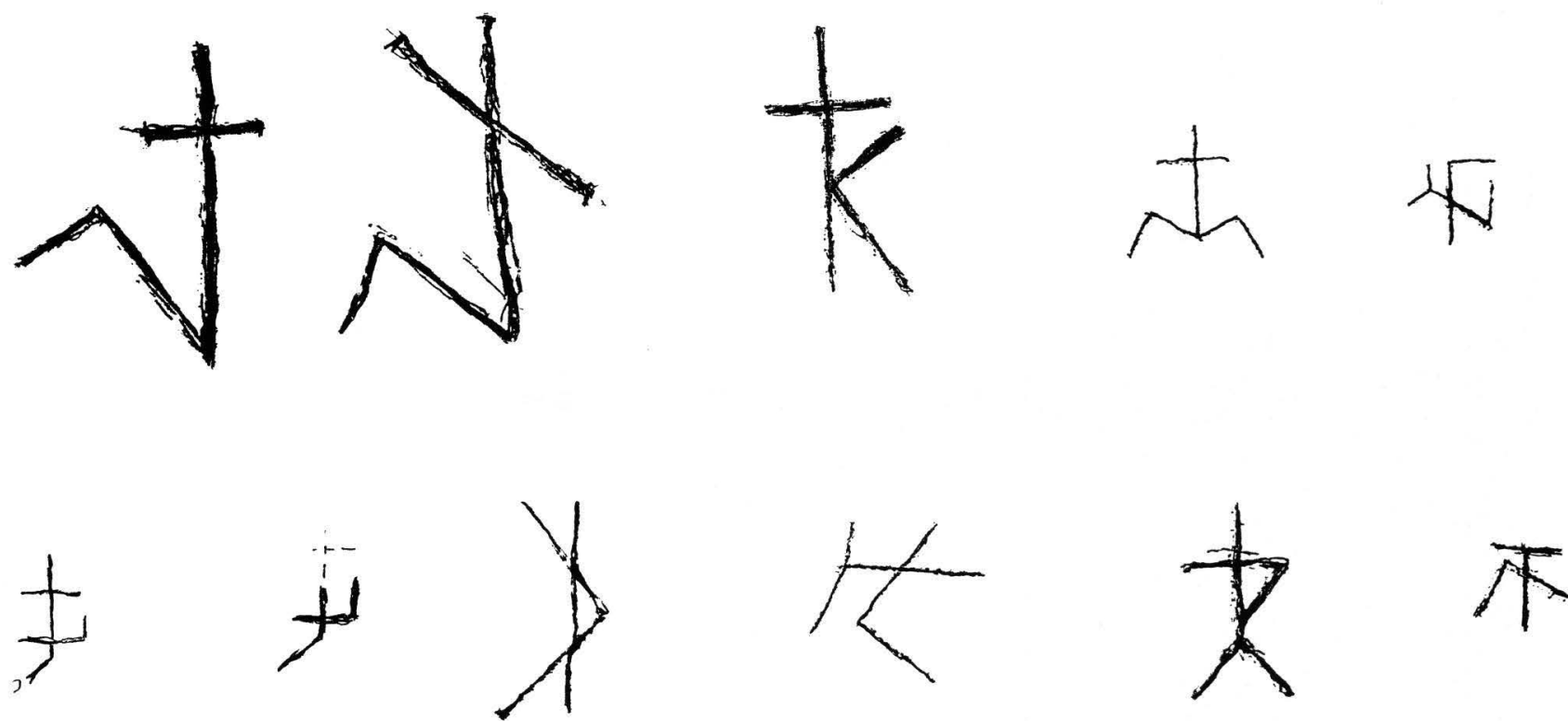

a
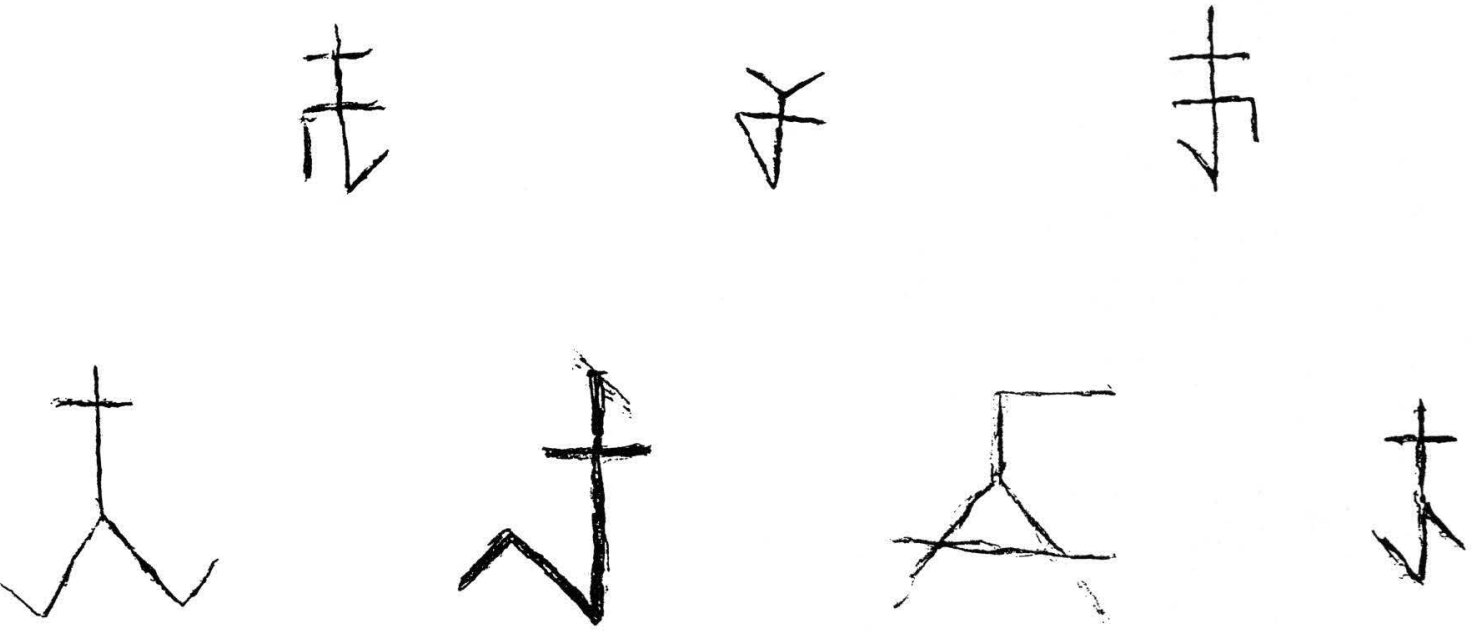

b

Abb. 7a. Abriebe von Steinmetzzeichen am oberen, aus glatten Quadern bestehenden Teil der Pfalzmauer von 1503-1510. - Aufnahme: M. Merki und D. Reicke. - Massstab 1:4.

Abb. 7b. Abriebe von Steinmetzzeichen am oberen Teil der Pfalzmauer bzw. am platzseitigen Flügel des Rathauses. - Aufnahme: M. Merki und D. Reicke. - Massstab 1:4. 


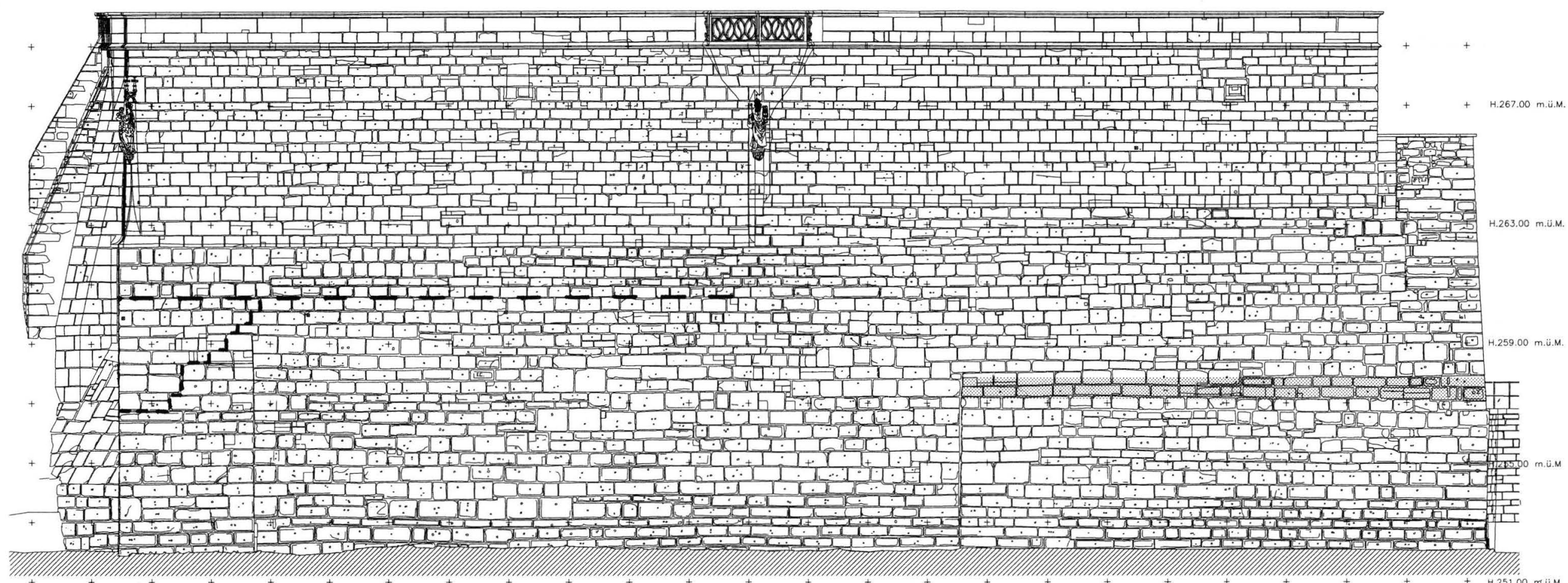

Abb. 8. Fotogrammetrische Aufnahme der Hauptfront, mit Befundeinträgen. Gestrichelt: mögliche Untergrenze des 1502-10 erneuerten Teils; grauer Raster: Zone des alten wulstförmigen Gesimses. - Aufnahme: Erik Schmidt, Umzeichnung: M. Merki. - Massstab 1:200. 
grosse, aber mehr rundlich geformte Zeichen wurden 1992 am Eselturm und an der Stadtmauer im Bereich des Barfüsserplatzes dokumentiert ${ }^{12}$. Gemäss den bis heute registrierten Befunden verändern sich die anfänglich rundlich bildhaften, oft auch Buchstaben enthaltenden Zeichen, wie sie an den romanischen Teilen des Münsters vorkommen, im Laufe des 13. Jahrhunderts zu schlichten, geradlinigen Formen. Im 14. Jahrhundert werden die Steinmetzzeichen wieder kleiner, aus Strichformen zusammengesetzt. Diesem Muster bleiben die Zeichen in vielzähligen Variationen bis in die Neuzeit treu. Die Zeichen am Eselturm gehören wegen der vereinzelten Werkzeugsymbole noch zur ersten Gruppe.

Abgesehen von der Grösse scheinen die Zeichen am Fuss der Pfalzmauer (Abb. 6) am ehesten mit jenen am ab 1273 erbauten Klingentalkloster vergleichbar zu sein. Hier wie dort sind Teile eines Quadrats, Winkel, pfeilähnliche Formen vorhanden; die Zeichen an der Pfalz sind allerdings bedeutend grösser als jene vom Klingental. Für einfache, kleine Zeichen wie Winkel o.ä. muss auch die Deutung als Versetzmarke in Betracht gezogen werden. Zeichen ähnlicher Grösse sind auch an der Stützmauer des Marthastifts (dendrochronologisch eruiertes Baudatum ca. letztes Viertel des 13. Jahrhunderts), abgesehen vom bereits erwähnten Stadtmauerabschnitt am Barfüsserplatz mit dem Eselturm (errichtet in der Mitte des 13. Jahrhunderts), festgestellt worden, also jeweils an Mauern aus Buckelquadern oder Quadern aus grobem Degerfeldersandstein ohne Buckel. Die derzeit möglichen Vergleiche scheinen nahezulegen, dass die vier alten Steinmetzzeichen an der Pfalzmauer in der zweiten Hälfte des 13. Jahrhunderts entstanden sind.

Ganz anders sehen die Zeichen aus, die am oberen, aus glatten Quadern bestehenden Teil der Mauer dokumentiert werden konnten (Abb. 7); anhand der Gegenüberstellung der Steinmetzzeichen von Abbildung 6 und 7 wird das unterschiedliche Alter der Werkstükke evident. Die Zeichen des oberen Teils können in das frühe 16. Jahrhundert datiert werden, weil fast die Hälfte davon auch am platzseitigen Flügel des Rathauses von 1504-1514 (Abb. 7b) vorkommt. Ein grosser Teil der Steinmetzen arbeitete offenbar an beiden Bauten gleichzeitig oder nacheinander.

\section{Der bauliche Befund}

Wegen der Quaderbauweise konnte der Mörtel, der die bloss millimeterdicken Fugen füllt, nicht als Nachweis für verschiedene Bauphasen dienen. Aufgrund des Quaderbildes, d.h. der Unregelmässigkeiten der Fugen, lässt sich aber mit einiger Wahrscheinlichkeit festhalten, dass der 1503 und in den folgenden Jahren erneuerte Teil einige Quaderreihen unter dem mittleren Kaffgesims beginnt (Abb. 8). Die Baumeister liessen demnach beim Neuaufbau einige Reihen aus alten Buckelquadern neu setzen, um eine gute Basis für

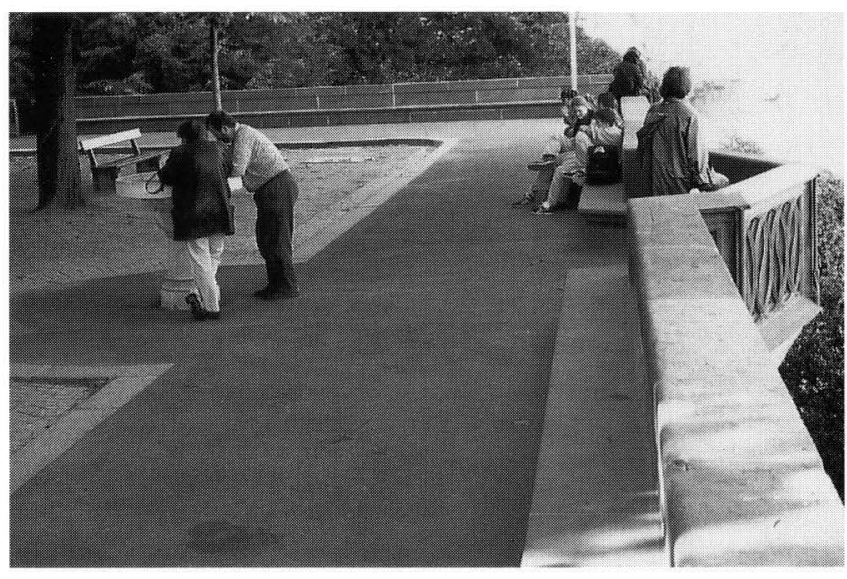

Abb. 9. Blick auf die Pfalzterrase mit der Kanzel (und dem sanierten Asphalt-Belag). - Foto: BaDpfl.

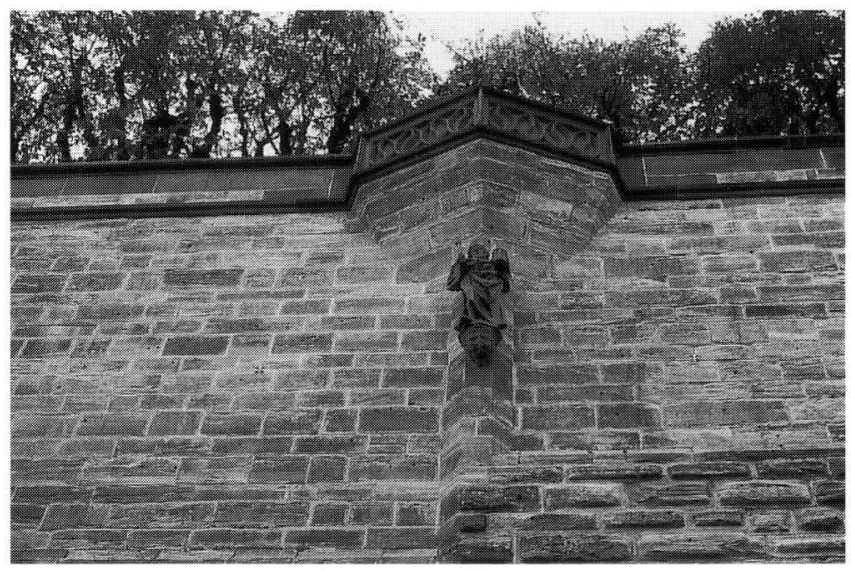

Abb. 10. Pfalzmauer (Ausschnitt). In der Mitte der Mauerfront die Kanzel und darunter die Statue Kaiser Heinrichs. - Foto: BaDpfl.

den darüber neu zu errichtenden Teil zu haben. (Weitere Unregelmässigkeiten konnten als Flicke des 18. und des 20. Jh. erkannt werden). - Deutlich jünger ist der Treppenanbau, dessen Wasserspeier inschriftlich auf 1723 datiert ist. An dieser Stelle muss aber - gemäss Merianplan (Abb. 3) von 1615, auf dem allerdings das untere Ende der Treppe nicht ersichtlich ist - schon vor 1723 ein Abgang bestanden haben.

Der untere Teil der Mauer besteht - wie die Datierung der Steinmetzzeichen nahelegt - aus mittelalterlichen Quadern. Kaum zu beurteilen ist, ob diese Quader seit der Errichtung im 13. Jahrhundert in situ geblieben sind. Die oben zitierten Quellen scheinen eher dagegen zu sprechen, v.a. die erwähnte Neufundamentierung in den Jahren 1467-69. Da in der Appenwiler-Chronik diesbezüglich vom Ausschöpfen von Wasser in der Fundamentgrube rund um die Uhr die Rede ist, muss 1467-1469 eine direkt am Rhein errichtete Stützmauer geflickt worden sein ${ }^{13}$. Es kann 
sich dabei um die grosse Stützmauer gehandelt haben, weil die Aufschüttung am Fuss der Pfalz (s. oben) erst bei den Arbeiten im Jahre 1510 entstanden ist. Da die Pfalz wie erwähnt auch Reste eines alten Gesimses besitzt, nehmen wir an, dass die Mauer 1467 nicht eingestürzt ist, sondern nur deren Fuss als Folge der Unterspülung geflickt werden musste. Der für 1502 überlieferte Einsturz der Pfalzmauer ereignete sich im Januar: Zumindest eine Ursache für den Einsturz dürfte daher das Gefrieren von in die Mauer eingedrungenem Wasser gewesen sein - aus dem gleichen Grund ist erst kürzlich, am 4. Februar 1997, die Stützmauer nahe bei der Pfalz, unterhalb des Ramsteinerhofs, in den Rhein gestürzt. Mehr über Umfang und Art der historischen Schäden an der Pfalz erfahren wir aus den Quellen nicht, und so bleibt auch der Umfang des schon 1346 erfolgten Einsturzes unbekannt.

Aus Baubefund und Quellen können wir also nicht eindeutig erschliessen, ob der untere Mauerteil wirklich aus dem Hochmittelalter stammt. Im Sinne eines „in dubio pro reo" und gestützt auf das alte wulstförmige Gesims (Abb. 8) halten wir fest, dass der untere Teil der Mauer aus dem 13. Jahrhundert stammen könnte.

\section{Zur Interpretation der Kanzel}

Abschliessend wenden wir uns der Kanzel an der Pfalz bzw. der Frage nach der von den Erbauern diesem Bauteil zugedachten Funktion zu (Abb. 9 und $A b b .10)$. Ein archäologischer Befund gibt nämlich Anlass zur Frage, ob 1503 anstelle der Aussichtskanzel nicht der Bau einer kleinen Kapelle geplant war. Der Befundplan (Abb. 11) zeigt die gut $2 \mathrm{~m}$ dicke Pfalzmauer, deren innere Front z.T. aus (alten) roh bearbeiteten Buckelquadern besteht. Im Bereich der Kanzel ist diese innere Flucht (im Boden) mit Ausnahme der obersten Steinlage des Fundamentes, welche geradeaus weiterverläuft, symmetrisch zum Vorsprung der Aussenseite (= Kanzel) ausgebildet (Abb. 11: Raster). In den Fugen der Fundamentpartie konnte ein spezieller eisenhaltiger Dichtungsmörtel festgestellt werden. - Aufgrund der Form des Fundaments ist deshalb in Betracht zu ziehen, dass hier anfänglich die Errichtung einer später nicht ausgeführten Kapelle vorgesehen war.

Als Vergleichsbeispiel für eine allfällige Kapelle sei die „Armbrusterkapelle" in Bern, eine 1503 auf der

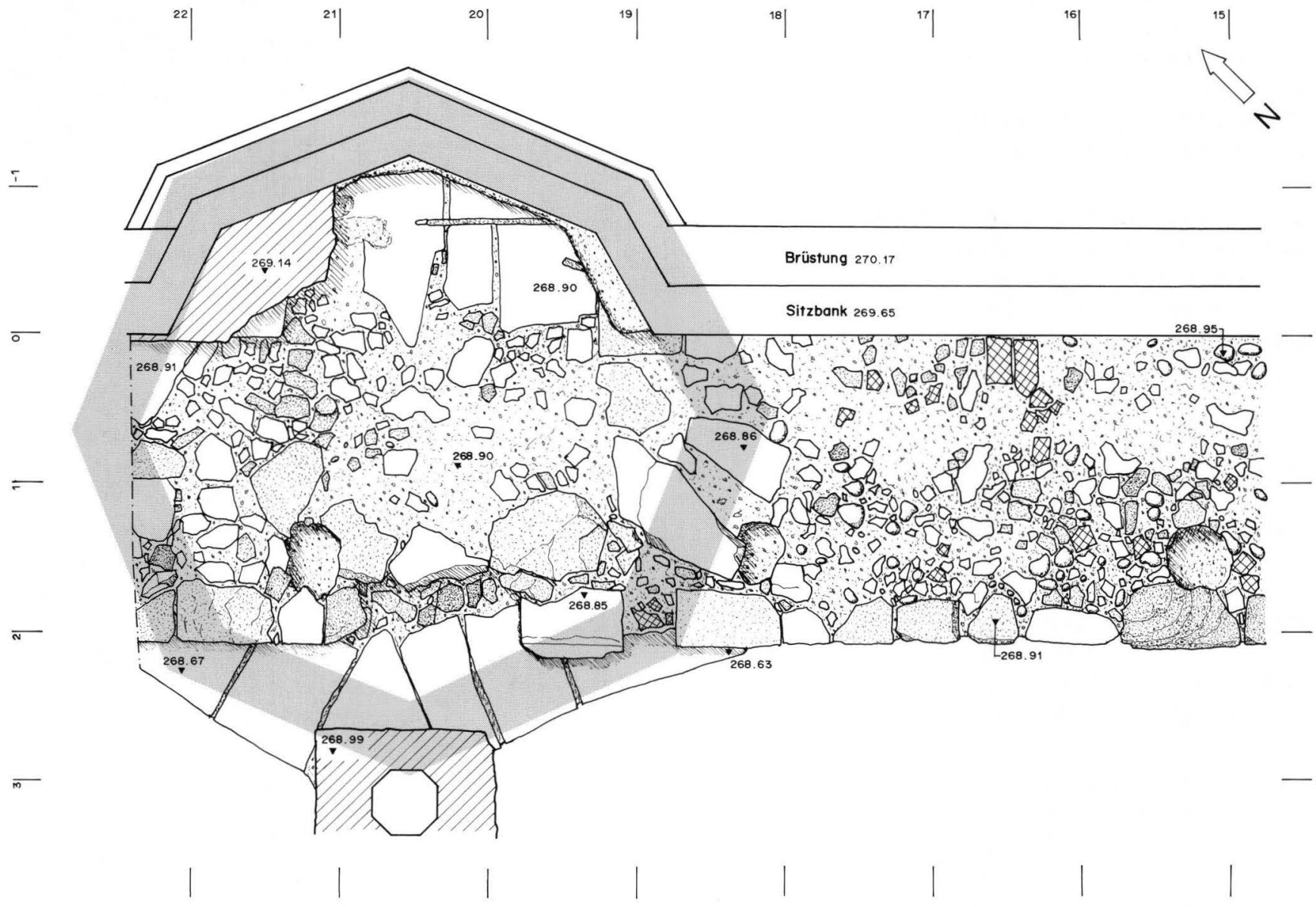

Abb. 11. Befundplan der Archäologischen Bodenforschung mit Rekonstruktion des Achteck-Baus. - Zeichnung: H. Eichin, nach Feldaufnahme von K. Kienzli. - Massstab: 1:50. 


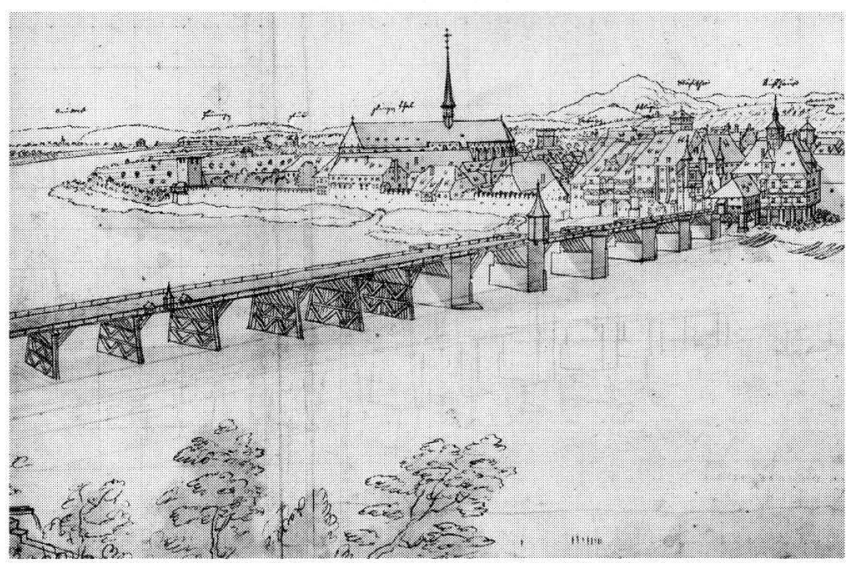

Abb. 12. Mittlere Brücke mit Käppelijoch. Zeichnung von E. Büchel, 1759.
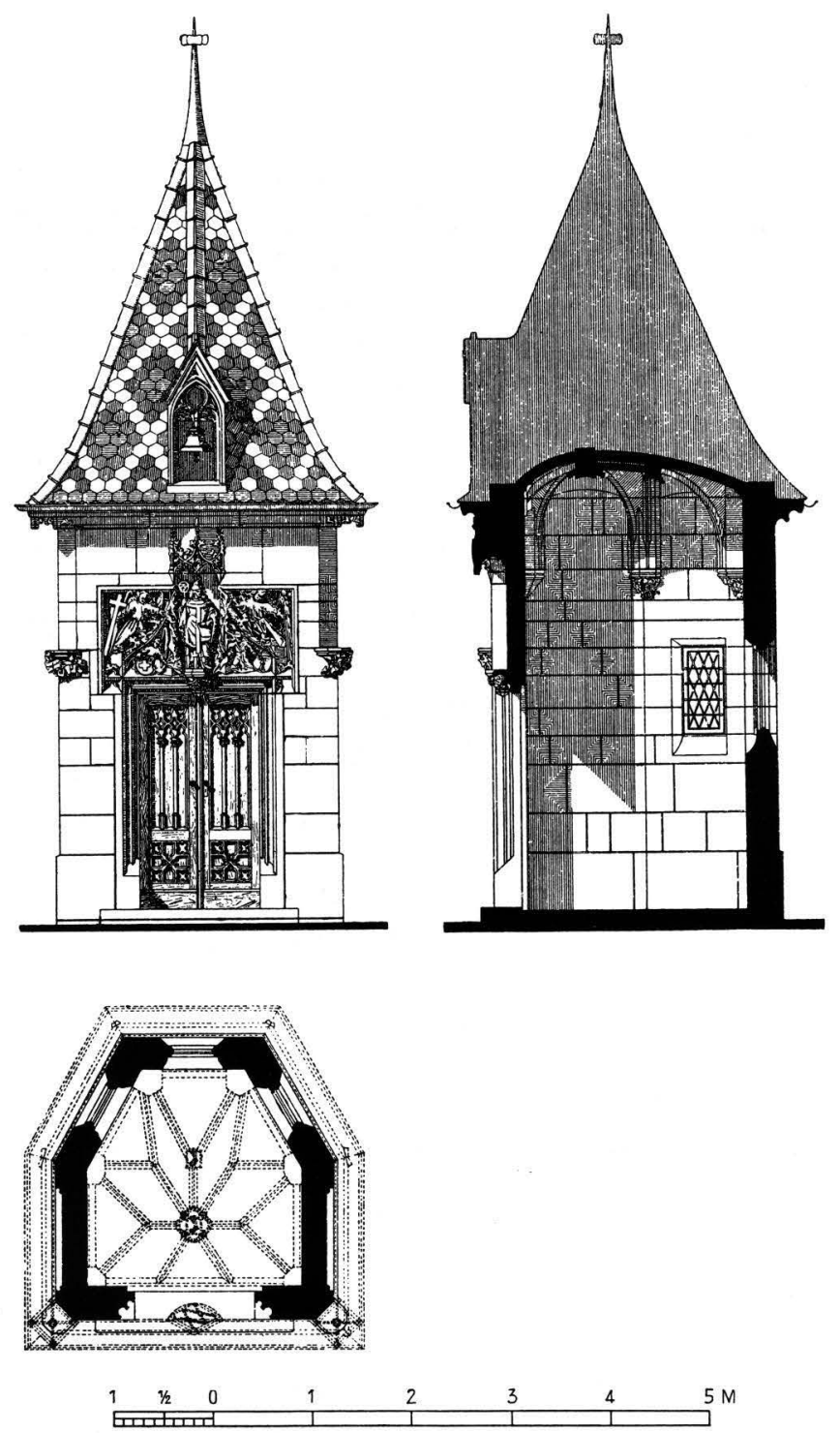

Abb. 13. Grundriss, Schnitt und Ansicht der Brückenkapelle im heutigen Zustand (aus: KDM BS, Bd. 1, 21971, 328 f. Abb. 13).
Südostecke der Münsterplattform erbaute Friedhofskapelle, erwähnt (1506 aus statischen Gründen bereits an einen anderen Ort versetzt) ${ }^{14}$. Diese Kapelle war sechseckig; mit etwas mehr als $5 \mathrm{~m}$ Innenbreite aber grösser als die hier postulierte Kapelle, die innen eine Breite von rund 3,6 m aufgewiesen hätte.

Ein weiteres naheliegendes Vergleichsbeispiel aus Basel ist das Käppelijoch (Abb. 12). Eine Kopie der ehemaligen Brückenkapelle steht heute auf der 1905 erneuerten Mittleren Brücke (Abb. 13). Das originale Käppelijoch kann anhand der erhalten gebliebenen Bauskulptur im Historischen Museum in das ausgehende 15. Jahrhundert datiert werden. Im Unterschied zur Kanzel der Pfalz wies das Käppelijoch den bei Kapellen üblichen, auf eine Hauptachse hin konzipierten rechteckigen Grundriss mit anschliessendem 3/8Polygonchor auf.

Ähnlich wie auf der Pfalz findet sich auch vor dem Chor der Martinskirche eine Kanzel (Abb. 14) ${ }^{15}$. Aufgrund der Gesimsprofile und der Bauweise, die im Dachraum eines der anstossenden Häuser registriert wurden, kann dieser Bau in das 13. oder 14. Jahrhundert datiert werden. Auch die Kanzel von St. Martin

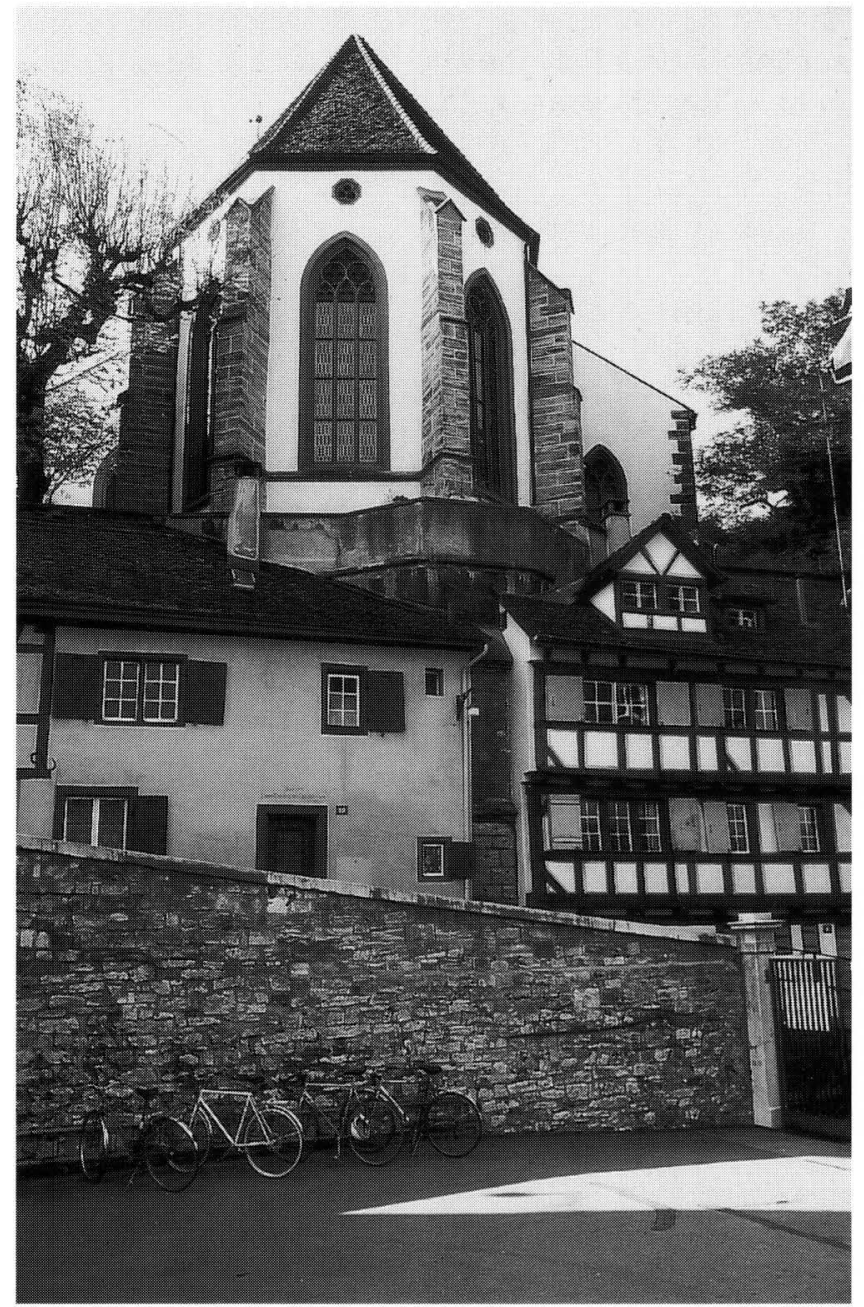

Abb. 14. Kanzel bei der Martinskirche, Ansicht vom Rheinsprung. - Foto: BaDpfl. 


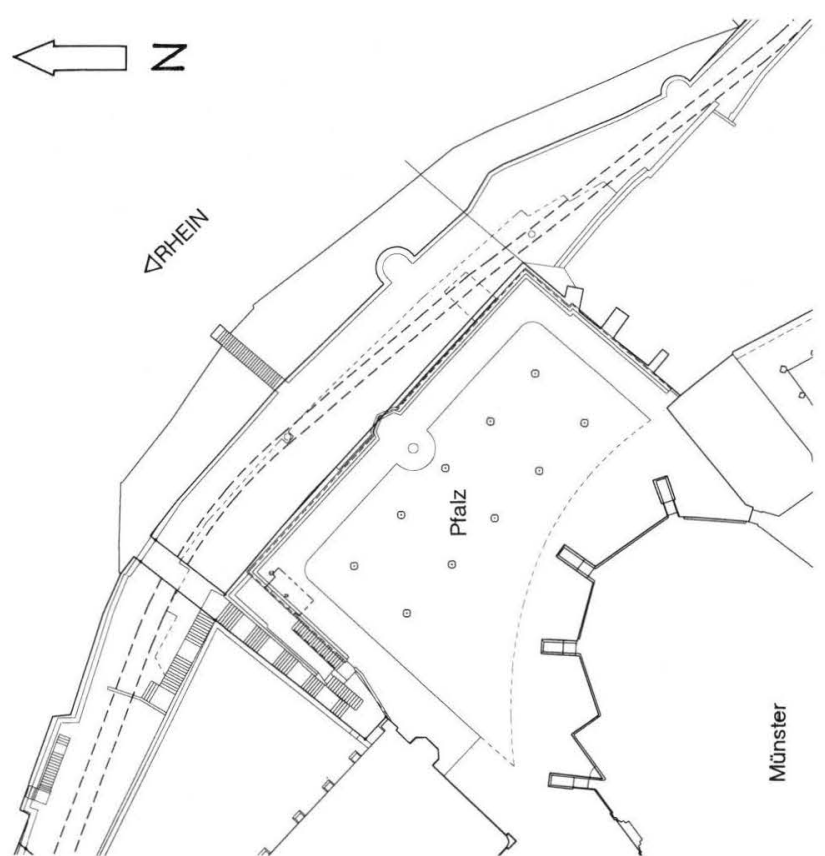

Abb. 15. Grundriss der Pfalz. - Zeichnung: U. Schön. - Massstab: 1:1000.

hat wie das Käppelijoch einen Grundriss mit gerade schliessendem Polygon und nicht eine Ecke des Polygons in der Mitte wie auf der Pfalz.

Erkerartig vorspringende Kapellenapsiden waren im Spätmittelalter häufig. Erhalten ist die Erkerkapelle der Johanniterkommende Rheinfelden, und am Basler Seidenhof kann anhand der Spuren ein spätmittelalterliches "Chörlein" zum Rhein hin angenommen werden.

Zurück zur Pfalz (Abb. 15). Die Deutung/Funktion dieser Kanzel ist unbekannt. Dass die Pfalz für - heute in Vergessenheit geratene - Volksbräuche benützt wurde, zeigt der Bericht von Daniel Fechter ${ }^{16}$ : Im 14. Jahrhundert soll bei Festen und Märkten abends auf der Pfalz getanzt worden sein, und Knaben sollen an der Fasnacht von hier aus Feuerscheiben geschlagen haben - ein Brauch, den wir heute noch aus dem Oberbaselbiet und aus der badischen Nachbarschaft kennen. Die Pfalz wurde somit schon in alter Zeit nicht nur kirchlich, sondern auch profan genutzt.

Zusammenfassend sei zur These einer Achteckkapelle anstelle der Kanzel festgehalten, dass einiges gegen diese Annahme spricht: Problematisch, wenn auch nicht unmöglich, wären der ungewöhnliche Zentralbau-Grundriss und dessen geringe Ausmasse; offen bleibt auch die Verwendung einer allfälligen $\mathrm{Ka}$ pelle, und schliesslich spricht die Tatsache, dass die oberste Steinlage des Fundaments sich dem Verlauf des Vorsprungs gegen das Münster hin nicht anpasst, sondern geradeaus weiterverläuft, dagegen. Falls hingegen die Errichtung bloss einer Kanzel von Anfang an konzipiert war, muss das seltsam nach innen vorspringende Fundament eine andere Erklärung finden. Es könnte meines Erachtens auf eine von den

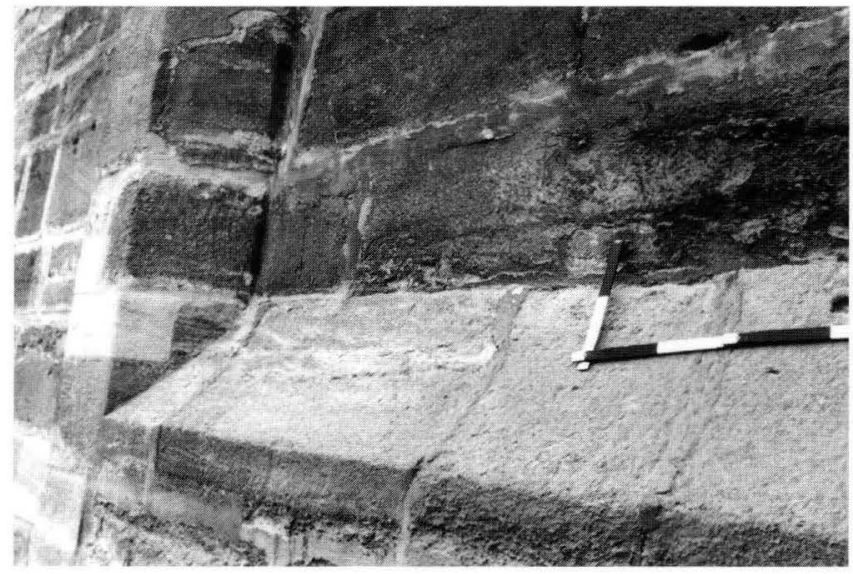

Abb. 16. Mittleres Kaffgesims in der nordwestlichen Hälfte der Pfalzmauer mit Eisenmörtel in den Fugen. Foto: BaDpfl.
Erbauern beabsichtigte bessere Statik der Kanzel zurückzuführen sein. Die Zusammengehörigkeit von Kanzel und oberer Pfalzmauer belegt der schon erwähnte Eisenmörtel, welcher vorwiegend am mittleren Kaffgesims (Abb. 16) verwendet worden ist und auch von Wurstisen als Besonderheit ausdrücklich (mit dem zugehörigen Rezept!) festgehalten wurde ${ }^{17}$.

Bei der Frage nach dem 1502 geplanten Verwendungszweck der Kanzel sollten wir die Funktion der Pfalzterrasse als Ganzes im Auge behalten: Auffallend ist ja, dass die Figur Kaiser Heinrichs den Ehrenplatz in der Mitte der Pfalzmauer erhielt. (Leider fehlt die Figur in der westlichen Ecke; dort könnte vielleicht die Statue von Heinrichs Frau Kunigunde oder besser noch Pantaleon als weiterer Stadtpatron angenommen werden.) Die Plazierung des Kaisers in der Mitte sollte möglicherweise einen hoheitlichen Aspekt des Bauwerks unterstreichen, oder - genauer - die Verbindung der Pfalz mit der Kathedrale als einer für den Bau der Kirche wichtigen Stützmauer verdeutlichen. Die Darstellung Heinrichs könnte sogar als Hinweis darauf zu verstehen sein, dass die erste Pfalzmauer gleichzeitig mit dem angeblich von Heinrich mitfinanzierten Neubau der Kirche im 11. Jahrhundert angelegt wurde, um der damals vergrösserten Kirche mehr Platz zu schaffen.

Auch wenn es sich bei der 1502 geplanten Kanzel in erster Linie um eine profane Aussichtsplattform handeln sollte, wäre doch eine Benutzung bei kirchlichen Feiern zu prüfen. Vielleicht diente die Kanzel auch bei einzelnen Zeremonien oder Prozessionen als Platz, um Hostien über dem Rhein vorzuführen. Ein Brauch dieser Art ist für die Westfassade des Münsters überliefert, wo eine Skulptur des Kirchengründers Heinrich ebenfalls an prominenter Stelle anzutreffen ist ${ }^{18}$. 


\section{Anmerkungen}

1 Die Arbeiten standen unter der Oberaufsicht des Münsterbaumeisters Peter Burckhardt, Bauleitung und Kontrolle: Marcial Lopez von der Münsterbauhütte. Beratung durch den Denkmalpfleger Dr. Alfred Wyss sowie den Vertreter der Eidgenössischen Denkmalpflege Prof. Alfred A. Schmid. An der Untersuchung waren beteiligt Hans Ritzmann (vorübergehend), Matthias Merki und Stephan Tramèr sowie Daniel Reicke (Sachbearbeiter). Die Dokumentation ist bei der Basler Denkmalpflege unter der Adresse Münsterplatz 9, Pfalz, D 1992/28, abgelegt.

2 Der Aushub wurde von der Archäologischen Bodenforschung beobachtet und der Befund dokumentiert; Sachbearbeiter: Guido Helmig.

3 Rudolf Wackernagel, Geschichte der Stadt Basel, Bd. 2.2, Basel 1916, 669.

4 Wackernagel (wie Anm. 3). - Daniel A. Fechter, "Topographie mit Berücksichtigung der Cultur- und Sittengeschichte", in: Basel im vierzehnten Jahrhundert, 18, Basel 1856: "Offenbar weist diese Name auf die Wohnung des Bischofs, die bischöfliche Pfalz hin, welche anfangs in dieser Gegend gestanden haben musste, vielleich diejenige, welche 1202 die Basler bei einem Auflaufe zerstörten...".

5 Karl Stehlin, Rudolf Wackernagel, Baugeschichte des Basler Münsters, hrsg. vom Basler Münsterbauverein, Basel 1895, 259. Christian Wurstisen, Analecta, "Ex libro fabricae summi templi Basil", S. 73 v. (Hier nach Stehlin/Wackernagel, ebda. 259 zitiert).

6 Stehlin/Wackernagel, wie Anm. 5, 258.

7 Der Einsturz von 1346 ist in verschiedenen Chroniken festgehalten (u.a. im Codex Beinheim, Universitätsbibliothek Basel, fol. 32v.) jener von 1502 in den Fabrikrechnungen des Münsters, die von Christian Wurstisen überliefert worden sind (Wurstisen, wie Anm. 5, 73 v.) Auch die umfassenden Arbeiten an der Pfalz in den Jahren 1467-1469 werden in diesen Fabrikrechnungen erwähnt, ohne dass allerdings ein Schaden als Anlass dafür genannt wird (Fabrikrechnungen de Jahre 1467/68 und 1469/70, nach Stehlin/Wackernagel, wie Anm. 5, 259)

8 Wurstisen, wie Anm. 5; in extenso auch bei Stehlin/Wackernagel, wie Anm. 5, 259-261.
9 Stehlin/Wackernagel, wie Anm. 5.

10 Stehlin/Wackernagel, wie Anm. 5

111503 war der bisherige Werkmeister Hans von Nussdorf gestorben; laut Wurstisen, wie Anm. 5, S. 72 "ward an seiner Statt zum Werckmeister aufgenommen M. Rumann Väsch, und sein Sohn Pauly für eine Parlier". R. Faesch ist in Basel ab 1476 nachgewiesen, er starb 1533; vgl. KDM BS, Bd. 1, Basel 1932, 390. Er war ab ca. 1493 Werkmeister des Thanner Münsters, was er auch nach 1503 blieb; die Ausführung der Pfalz lag also wohl mehr in den Händen des Sohns, der spätestens 1509 Werkmeister des Basler Münsters wurde, vgl. Stehlin/Wackernagel, wie Anm. 5, 262 f.

12 Christoph Ph. Matt, Christian Bing, "Die archäologischen Untersuchungen im Bereich des Energieleitungstunnels (ELT) Gerbergasse - Barfüsserplatz - Steinenberg, 1991/2, Vorbericht", JbAB 1992, 85-105, insbesondere Abb. 10.

13 Die Chronik Erhards von Appenwiler 1439-1471, in: Basler Chroniken, Bd. 4, 249-359, 350, Leipzig 1890. - In der Münster-Fabrikrechnung von 1467/68 wird dieselbe Arbeit wiederholt mit "opus circa renum" bezeichnet, nur 1469/70 lautet der Eintrag: "von der Quaderstein wegen, so zu der Pfalz gebrucht sind"; vgl. Stehlin/Wackernagel, wie Anm. 5, 259

14 Daniel Gutscher, "Historische Notizen zur Plattform", in: Urs Zumbrunn, Daniel Gutscher, Bern, Die Skulpturenfunde der Münsterplattform, 12 f., Bern 1994.

15 Sie konnte kürzlich teilweise untersucht werden. Laufnummer D 1993/13, Dokumentation bei der Basler Denkmalpflege.

16 Fechter, wie Anm. 4, 22.

17 "Unnd dieweil der zeug, mit welchem die blatten auf der hauptmauer, wunderhart und eisenmässig, hab ich auss dem fabricbuch zwey recept ...", Christian Wurstisen, Beschreibung des Basler Münsters und seiner Umgebung, hrsg. von Rudolf Wackernagel, Beiträge zur vaterländischen Geschichte 12, N.F. 2, Basel 1888, 469: Grünspan, Stahlspäne und Steinmehl oder Ziegelmehl in Essig angerührt.

18 Ich danke François Maurer für seine freundlichen Hinweise. Zu Prozessionen im Münster und im Kreuzgang siehe Regine Abegg "Funktionen des Kreuzgangs im Mittelalter - Liturgie und Alltag", Kunst und Architektur in der Schweiz 48, 1997.2, 6-24. 


\section{Anhang}

\section{Abkürzungen}

AB Archäologische Bodenforschung

BaDpfl. Basler Denkmalpflege

BS Bodenscherbe

FK Fundkomplex

Fl. Fläche

$\mathrm{H} \quad$ Horizont

HGB Historisches Grundbuch

$\mathrm{HMB}$ Historisches Museum Basel

Inv.-Nr. Inventar-Nummer

$\mathrm{Jb} \quad$ Jahresbericht

KMBL Kantonsmuseum Basel-Land

Mk Münzkabinett (HMB)

MR Mauer

MVK Museum für Völkerkunde

NHM Naturhistorisches Museum

OF Oberfläche

OK Oberkante

P Profil

RMA Römermuseum Augst

RS Randscherbe

Sd Sonderdruck

SS Sondierschnitt

StAB(S) Staatsarchiv Basel-Stadt

UK Unterkante

WS Wandscherbe

Literatursigel (Zeitschriften, Reihen etc.)

ABS Archäologie in Basel. Materialhefte zur Archäologie in Basel

AS Archäologie der Schweiz

ASA Anzeiger für Schweizerische Altertumskunde

(B)Njbl. (Basler) Neujahrsblatt. Herausgegeben von der Gesellschaft zur Beförderung des Guten und Gemeinnützigen.

BUB Urkundenbuch der Stadt Basel, Bände 111. Herausgegeben von der Historischen und Antiquarischen Gesellschaft zu Basel, Basel.

BZ Basler Zeitschrift für Geschichte und Altertumskunde

JbAB Jahresbericht der Archäologischen Bodenforschung des Kantons Basel-Stadt

JbAK Jahresberichte aus Augst und Kaiseraugst

JbHMB Jahresbericht des Historischen Museums Basel-Stadt

JbSGUF Jahresbericht der Schweizerischen Gesellschaft für Ur- und Frühgeschichte

KDM BS Die Kunstdenkmäler des Kantons BaselStadt, Bände 1-5. Herausgegeben von der Gesellschaft für Schweizerische Kunstgeschichte, Basel.
NSBV Nachrichten des Schweizerischen Burgenvereins

SBKAM Schweizer Beiträge zur Kulturgeschichte und Archäologie des Mittelalters

ZAK Zeitschrift für Schweizerische Archäologie und Kunstgeschichte

ZAM Zeitschrift für Archäologie des Mittelalters

\section{Schriften der Archäologischen Bodenforschung}

Jahresberichte (JbAB)

Der Jahresbericht 1994 kann, solange vorrätig, zum Preis von Fr. 40.- bei der Archäologischen Bodenforschung bezogen werden. Die Jahresberichte 1988 bis 1993 sind zu Fr. 10.- noch erhältlich.

Materialhefte zur Archäologie in Basel (ABS)

Ergänzend zu den Jahresberichten wird in den Materialheften zur Archäologie in Basel eine repräsentative Auswahl von Basler Fund- und Dokumentationsmaterial vorgelegt. Mit der Schriftenreihe soll die abschliessende Berichterstattung über eine Grabung mit nachvollziehbarer Beweisführung und Auswertung des Fundmaterials ermöglicht werden.

Bisher erschienen und solange vorrätig noch erhältlich

Rudolf Moosbrugger-Leu, Die Chrischonakirche von Bettingen. Archäologische Untersuchungen und baugeschichtliche Auswertung. Mit einem Beitrag von Beatrice Schärli über die Münzfunde. Verlag Archäologische Bodenforschung Basel-Stadt, Basel 1985. Materialhefte zur Archäologie in Basel, Heft 1. 110 Textseiten, 78 Abbildungen, 6 Fototafeln und 3 Faltpläne. ISBN 3-905098-00-8. Fr. 15.-

Rudolf Moosbrugger-Leu, Peter Eggenberger, Werner Stöckli, Die Predigerkirche in Basel. Mit einem Beitrag von Beatrice Schärli über die Münzfunde. Verlag Archäologische Bodenforschung Basel-Stadt, Basel 1985. Materialhefte zur Archäologie in Basel, Heft 2. 133 Textseiten, 108 Abbildungen, 5 Faltpläne. ISBN 3-905098-01-6. Fr. 15.-

Peter Thommen, Die Kirchenburg von Riehen. Mit Beiträgen von Kurt Wechsler und Marcel Mundschin. Verlag Archäologische Bodenforschung Basel-Stadt, Basel 1993. Materialhefte zur Archäologie in Basel, Heft 5. 172 Textseiten, 135 Abbildungen, 15 Tafeln. ISBN 3905098-08-3. Fr. 40.-.

Thomas Maeglin, Spätkeltische Funde von der Augustinergasse in Basel. Mit einem osteologischen Beitrag von Jörg Schibler. Verlag Archäologische Bodenforschung Basel-Stadt, Basel 1986. Materialhefte zur Archäologie in Basel, Heft 6. 97 Textseiten, 33 Abbildungen, 14 Tafeln. ISBN 3-905098-02-4. Fr. 15.-

Dieter Holstein, Die bronzezeitlichen Funde aus dem Kanton BaselStadt. Verlag Archäologische Bodenforschung Basel-Stadt, Basel 1991. Materialhefte zur Archäologie in Basel, Heft 7. 95 Textseiten, 17 Abbildungen, 36 Tafeln, 1 Faltplan. ISBN 3-905098-09-1. Fr. 15.-.

Jacqueline Reich, Archäozoologische Auswertung des mittelalterlichen Tierknochenmaterials (10.-13. Jh.) von der Schneidergasse 8, 10 und 12 in Basel ( $\mathrm{CH}$ ). Mit einem Beitrag von Christoph Ph. Matt. 
Verlag Archäologische Bodenforschung des Kantons Basel-Stadt, Basel 1995. Materialhefte zur Archäologie in Basel, Heft 8. 84 Textseiten, 75 Abbildungen, 74 Tabellen. ISBN 3-905098-15-6. Fr. 45.-.

René Matteotti, Die Alte Landvogtei in Riehen. Ein archäologischer Beitrag zum Alltagsgerät derNeuzeit. Verlag Archäologische Bodenforschung des Kantons-Basel-Stadt, Basel 1994. Materialhefte zur Archäologie in Basel, Heft 9. 82 Textseiten, 56 Abbildungen, 33 Tafeln, 2 Farbtafeln. ISBN 3-905098-14-8. Fr. 40.-.

Pia Kamber, Die Latrinen auf dem Areal des Augustinerklosters, Basel-Augustinergasse 2, Grabung 1968. Mit einem Beitrag von F. Maurer zur Baugeschichte des Klosters. Weitere Beiträge von S. Jacomet (Archäobotanik), M. Joos (Sedimentologie), J. Schibler (Archäozoologie) und W.B. Stern (Archäometrie). Verlag Archäologische Bodenforschung des Kantons Basel-Stadt, Basel 1995. Materialhefte zur Archäologie in Basel, Heft 10. 153 Textseiten, 111 Abbildungen, 52 Tafeln, 5 Farbtafeln, 1 Falttafel. ISBN 3-905098-17-2. Fr. 45.-.

Marlu Kühn, Spätmittelalterliche Getreidefunde aus einer Brandschicht des Basler Rosshof-Areales (15. Jahrhundert AD). Verlag Archäologische Bodenforschung des Kantons Basel-Stadt, Basel 1996. Materialhefte zur Archäologie in Basel, Heft 11.78 Textseiten, 43 Abbildungen/ Diagramme, 87 Zeichnungen, 19 Tabellen. ISBN3-905098-19-9. Fr.45.-

Weitere Veröffentlichungen der Archäologischen Bodenforschung des Kantons Basel-Stadt

Rolf d'Aujourd'hui, Archäologie in Basel. Fundstellenregister und Literaturverzeichnis. Jubiläumsheft zum 25jährigen Bestehen der Archäologischen Bodenforschung Basel-Stadt. Herausgegeben von der Archäologischen Bodenforschung Basel-Stadt mit Unterstützung der Historischen und Antiquarischen Gesellschaft zu Basel. Verlag Archäologische Bodenforschung Basel-Stadt, Basel 1988. 179 Seiten, 5 Abbildungen. ISBN 3-905098-04-0. Fr. 10.-

Rolf d'Aujourd'hui, Die Entwicklung Basels vom keltischen Oppidum zur hochmittelalterlichen Stadt. Überblick Forschungsstand 1989. Zweite überarbeitete Auflage. Verlag Archäologische Bodenforschung Basel-Stadt, Basel 1990. 25 Textseiten, 35 Abbildungen. ISBN 3905098-05-9. Fr. 10.-. (Zur Zeit vergriffen, Neuauflage in Vorbereitung.)

Rolf d'Aujourd'hui, Basel Leonhardsgraben 47: Eine Informationsstelle über die mittelalterliche Stadtbefestigung im Teufelhof, Führer zur Ausstellung, Sd aus: Unsere Kunstdenkmäler 41, 1990.2, 169-180. Fr. 3.-
Rolf d'Aujourd'hui, Der Archäologische Park am Murus Gallicus, Führer durch die Ausstellung an der Rittergasse in Basel, Sd aus: Basler Stadtbuch 1993, 196-204. Fr. 3.-.

Ulrike Giesler-Müller, Das frühmittelalterliche Gräberfeld BaselKleinhüningen. Katalog und Tafeln. Basler Beiträge zur Ur- und Frühgeschichte, Bd. 11 B. Habegger Verlag, Derendingen-Solothurn 1992 221 Textseiten, 113 Tafeln, 1 Faltplan. ISBN3-85723-321-4. (Nur über Buchhandelerhältlich.)

Peter Jud (Hrsg.), Die spätkeltische Zeit am südlichen Oberrhein/Le Rhin supérieur à la fin de l'époque celtique, Kolloquium Basel, 17./18. Oktober 1991/Colloque de Bâle, 17/18 octobre 1991. Zweite, unveränderte Auflage. Verlag Archäologische Bodenforschung des Kantons Basel-Stadt, Basel 1995. 179 Seiten, zahlreiche Abbildungen. ISBN 3-905098-13-X. Fr. 40.-.

\section{Bestellmöglichkeiten}

Die Hefte werden von der Archäologischen Bodenforschung und vom Seminar für Ur- und Frühgeschichte der Universität Basel im Selbstverlag herausgegeben und sind über den Buchhandel oder beim Verlag direkt erhältlich. Bestellungen sind zu richten an: Archäologische Bodenforschung Basel-Stadt, Petersgraben 11, 4051 Basel.

Einzelbestellung. Es gelten die oben erwähnten Preise zuzüglich Versandkosten.

Abonnement Materialhefte. Der Preis je Heft beträgt Fr. 35.- zuzüglich Versandkosten. Die Auslieferung erfolgt jeweils nach Erscheinen eines Heftes.

Abonnement Jahresbericht. Der Preis je Jahrgang beträgt Fr. 30.- zuzüglich Versandkosten.

Wenn Sie Jahresbericht und Materialheft abonniert haben, gewähren wir Ihnen einen Rabatt von Fr. 10.auf den Abonnements-Preis des Jahresberichtes. 